\title{
Histochemical localization of copper in the gastrointestinal tract of the rat
}

\author{
A. OLUFEMI WILLIAMS ${ }^{1}$ \\ From the Department of Pathology, Queen's University, Belfast
}

SYNOPSIS Three histochemical reactions for the localization of copper were applied to liver and different parts of the gastrointestinal tract of normal as well as of rats poisoned with a solution of copper. Variable quantities of copper were demonstrated in the livers of all the poisoned rats and in 21 out of 24 sections of jejunum. Rubeanic acid counterstained with $0.5 \%$ Cresyl violet gave the best results. Copper was not demonstrable in the livers or the gastrointestinal tract of normal rats. $\bigcirc$ As the metal was concentrated in the upper jejunum, it is likely that this is the site of absorption. Detection of this metal may assist in the diagnosis of hepatolenticular degeneration.

An important landmark in the investigation of Wilson's disease was the finding of an increase in copper content of the liver (Rumpel, 1913). Bearn and Kunkel (1955) demonstrated excessive absorption of copper in patients with Wilson's disease by using radioactive copper, later confirmed by Maytum Goldstein, McGuckin, and Owen (1961). Using $\mathrm{Cu}_{64}$, Scheinberg and Morrell (1957) found that in patients with Wilson's disease a gradient of concentration in the intestinal mucosa ensures that more copper is absorbed from the gut into the blood than is normal. Bickel (1961), however, said that he had never been convinced that intestinal copper 'uptake' was increased in Wilson's disease. There are no published reports of the histochemical localization of the metal in the gastro-intestinal tract. Howell (1959) stated that copper had never been observed in the gastrointestinal mucosa of rats, but as increased amounts of copper are deposited in the livers of rats with simple copper poisoning (Bournville, and Yvon 1875; Wolff, 1960), there is strong presumptive evidence of intestinal absorption. The purpose of this study is to localize copper by histochemical methods in the gastrointestinal tract of rats given poisonous doses of copper.

\section{MATERIALS AND MĖTHODS}

A single batch of male Wistar rats, average body weight $110 \mathrm{~g}$., was divided randomly into two groups of 24 each. The animals were individually caged and housed in an open colony at an even temperature of $70^{\circ} \mathrm{F}$. One

'Present address: Department of Pathology, University of Ibadan, Ibadan, Nigeria.

Received for publication 10 June 1965. group, normal control, was fed the normal laboratory diet of calf nuts and given ordinary drinking water $\vec{\theta}$ throughout the experiment. The other group was fed the of normal laboratory diet of calf nuts but had $0.2 \%$ copper acetate solution, prepared once a week, substituted for drinking water. The total quantity of fluid taken was not strictly recorded. The experiment lasted for $\mathbf{3 2 0}$ days. At the end of the experiment all the animals were killed and necropsied.

Sections were taken from the liver, stomach, jejunum, ileum, and colon and stained by the three histochemical methods for copper based on rubeanic acid (Uzman, 1956; Howell, 1959), sodium diethyldithiocarbamate, and p-dimethylaminobebzylidenerhodanine (Howell, 1959). They were also stained for haemosiderin by the method of Perls (1867) as modified by Gömöri (1936).

The copper content of the liver in test rats was estimated by the method of Eden and Green (1940) and controlled by estimations on the control rats. Specimens of liver were taken from the different lobes of the liver

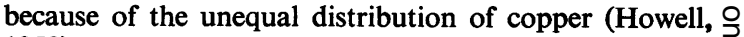
1959).

\section{RESULTS}

The animals drank the solution without showing any ill effects. Evidence of absorption of copper is seen in the increased hepatic copper content of the test rats (Table I) and histochemical demonstration of copper in the liver (Fig. 1).

HISTOLOGY Variable amounts of copper were $\stackrel{\mathscr{\&}}{+}$ demonstrable in the mucosa of the jejunum (Fig. 2) $\frac{T}{0}$ of 21 test rats. The granules were seen in the cyto- $\frac{\text { ㅇ }}{\mathbb{D}}$ plasm of the epithelial cells or close to their nuclei. $\stackrel{?}{\square}$ With rubeanic acid they stained black (Fig. 2), with $\stackrel{\unrhd}{\square}$ sodium diethyldithiocarbamate yellowish-brown, 
TABLE I

AVERAGE COPPER CONTENT OF LIVER IN CONTROL AND COPPER-POISONED RATS ${ }^{1}$

\begin{tabular}{llllll}
$\begin{array}{l}24 \text { Control } \\
\text { Rats }(C)\end{array}$ & $\begin{array}{l}24 \text { Test } \\
\text { Rats }(T)\end{array}$ & $\begin{array}{l}\text { Difference } \\
\text { Between } \\
\text { Means } \\
(T-C)\end{array}$ & $t$ & $\begin{array}{l}P= \\
\text { Probability }\end{array}$ \\
\hline Liver & $\begin{array}{l}\text { 10.8 S.D. } \\
0.89\end{array}$ & $\begin{array}{l}369 \cdot 3 \\
38\end{array}$ & 358.5 & 9.4 & $<0.001$
\end{tabular}

${ }^{1}$ Results expressed in $\mu \mathrm{g} . / \mathrm{g}$. of wet tissue.

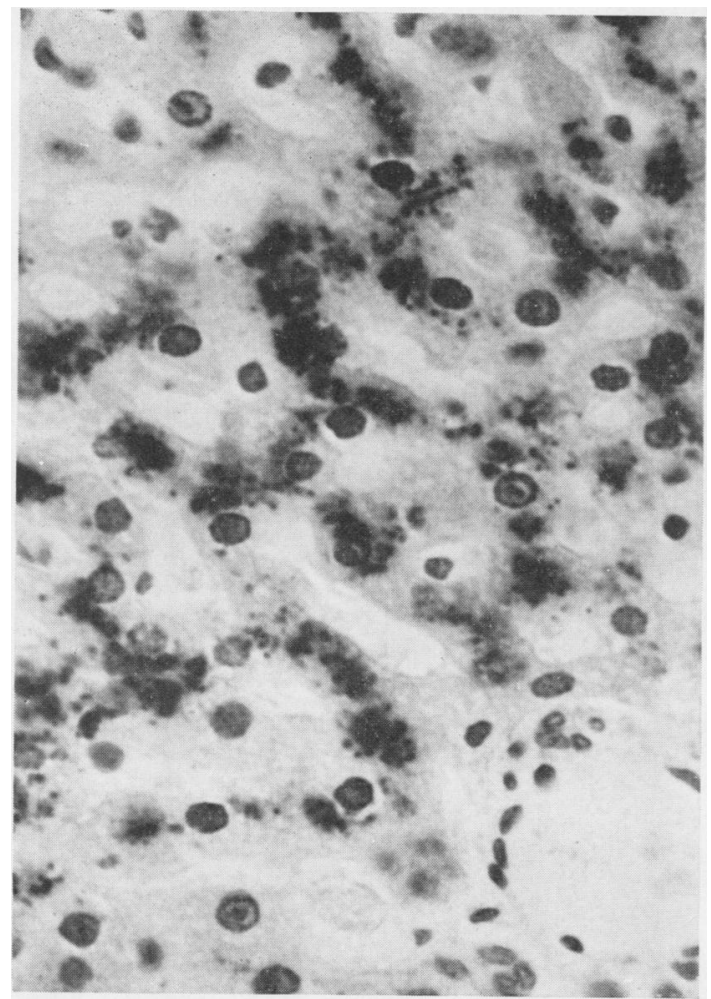

FIG. 1. Histochemical localization of copper in hepatic cells; granules staining black are grouped around the nuclei. Rubeanic acid and neutral red $\times 670$.

and with p-dimethyl-benzylidenerhodanine, as reddish granules. There was no specific pattern of distribution in the villi. Occasionally, copper was seen in the submucosa. The muscular layers of the intestine showed no copper. Haemosiderin granules were not easily demonstrable but a few were seen in stomach, jejunum, and ileum.

Copper was not demonstrable in the stomach, ileum, or colon of the test rats by any of the histochemical methods, nor in any part of the gastrointestinal tract of the controls.

The normal rat liver does not contain histochemically demonstrable copper but in the liver of rats poisoned with copper, it is stored mainly in the parenchymal cells (Fig. 1). There is no predilection for any zone of the lobule.

\section{DISCUSSION}

Copper in tissues is mostly bound to protein and the

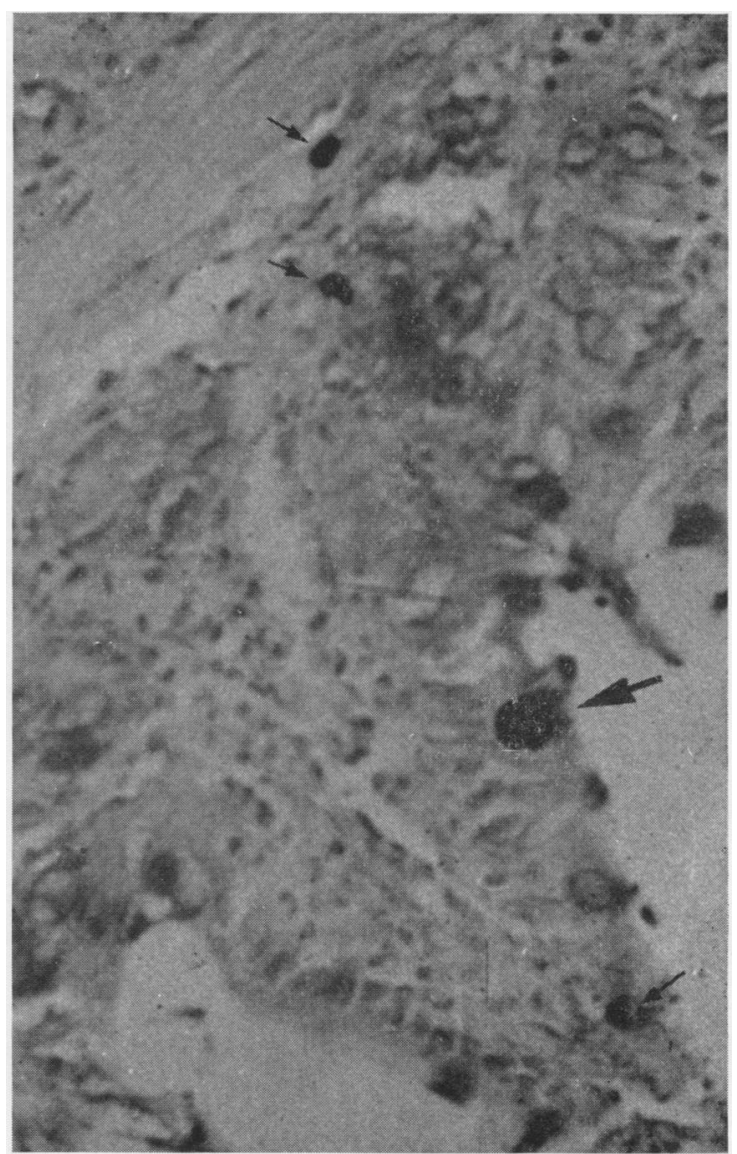

FIG. 2. Histochemical localization of copper in upper jejunum. Note copper granules in the mucosa and submucosa. Rubeanic acid and cresyl violet $\times 200$.

copper protein complexes may be unreactive on histochemical testing. Release of the copper has been attempted (Gömöri, 1952; Uzman, 1956) but with little success. However, copper is usually detectable by histochemical methods if present in abnormal amounts in experimental animals.

At least four compounds have been recommended for the histochemical detection of copper (Okamoto and Utamura, 1938; Waterhouse quoted by Howell, 1959; Uzman, 1956; Howell, 1959). Three of these have been employed in its detection and localization 
in the liver and gastrointestinal tract of the rat but none is specific for copper since they all form coloured complexes with other metals; iron is perhaps the most likely to cause confusion (Howell, 1959). In the present study, at least two of the three reactions were convincingly positive before the presence of copper was accepted.

Copper was not detectable in normal rats. In the test rats, there is evidence that by giving copper orally increased amounts are deposited in the tissues and the increased amounts in the liver also strongly indicate absorption from the intestine. The absence of histochemically detectable copper in other parts of the gut excepting the jejunum is striking. Although no quantitative estimation of copper was carried out there was an impression that more granules of copper were seen in the upper part of the jejunum than in the ileum.

The amount of detectable copper in the different rats varied, but large quantities were not seen. The rubeanic acid method of Uzman counterstained with $0.5 \%$ Cresyl violet gave the best results.

The quantity of copper localized in the liver does not seem to bear any relationship to the quantity detectable in the jejunum. In fact, three rats with a considerably raised hepatic copper content showed no detectable copper in the gastrointestinal tract. The experiment illustrates that copper can be detected in the upper jejunum, and, since it appears to be found here alone, there is a possibility that this is the site of absorption.

There do not appear to be any reports on the localization of copper in jejunal biopsies of patients with Wilson's disease, and this procedure may be a useful adjunct in the diagnosis of hepatolenticular degeneration.

I wish to thank Professor J. H. Biggart, Professor R. A. Q. O'Meara, and Mr. D. W. Neill for their help and advice. I am also grateful to Mr. D. Mehaffey for the photographs.

\section{REFERENCES}

Bearn, A. G., and Kunkel, H. G. (1955). J. Lab. clin. Med., 45, 623. Bickel, H. (1961). In Wilson's disease-Some Current Concepts, edited by J. M. Walshe and J. N. Cumings, p. 58. Blackwell, Oxford. Bournville, and Yvon (1875). J. Pharm. Chim. (Paris), 21, 414.

Eden, A., and Green, H. H. (1950). Biochem. J., 34, 1202.

Gömöri, G. (1936). Amer. J. Path., 12, 655.

- (1952). Microscopic Histochemistry. p. 35. Chicago University Press.

Howell, J. S. (1959). J. Path. Bact., 77, 473.

Maytum, W. J., Goldstein, N. P., McGuckin, W. J., and Owen, C. A Jr. (1961). Proc. Mayo Clin., 36, 641.

Okamoto, K., and Utamura, M. (1938). Acta Sch. med. Univ. Kioto, 20, 573.

Perls, M. (1867), Virchows Arch, path. Anat, 39, 42.

Rumpel, A. (1913). Dtsch. Z. Nervenheilk., 49, 54-73.

Scheinberg, I. H., and Morrell, A. G. (1957). J. clin. Invest., 36, 1193.

Uzman, L. L. (1956). Lab. Invest., 5, 299.

Wolff, S. M. (1960). Arch. Path., 69, 217. 